\title{
Identification of a Novel Keratin 9 Missense Mutation in a Chinese Family with Epidermolytic Palmoplantar Keratoderma
}

\author{
Heng Xiao ${ }^{a, b, c}$ Yi Guo ${ }^{d}$ Junhui Yie Hong Xia ${ }^{a}$ Hongbo Xu ${ }^{a}$ Lamei Yuan ${ }^{a}$ \\ Pengzhi Hua Zhijian Yang ${ }^{a}$ Zhenghao He ${ }^{a}$ Hongwei Lu ${ }^{a}$ Hao Denga,b
}

${ }^{a}$ Centre for Experimental Medicine, the Third Xiangya Hospital, Central South University, Changsha, Hunan, 'Department of Neurology, the Third Xiangya Hospital, Central South University, Changsha, Hunan, 'Department of Pathology, the Third Xiangya Hospital, Central South University, Changsha, Hunan, dDepartment of Medical Information, Information Security and Big Data Research Institute, Central South University, Changsha, Hunan, eDepartment of Ophthalmology, the Third Xiangya Hospital, Central South University, Changsha, Hunan, China

\section{Key Words}

Epidermolytic palmoplantar keratoderma - KRT9 gene - Exome sequencing • Genetic counseling $\cdot$ Keratin filament network $•$ Dominant negative effect

\begin{abstract}
Background/Aims: Epidermolytic palmoplantar keratoderma (EPPK) is an autosomal dominant genodermatosis. It is characterized by diffuse yellow keratoses on the palmoplantar epidermis, with an erythematous border. The keratin 9 gene (KRT9) and less frequently the keratin 1 gene (KRT1) are responsible for EPPK. This study aims to identify and analyse genetic defects responsible for EPPK in a Han Chinese pedigree. Methods: A four-generation Han Chinese pedigree containing five individuals affected with EPPK was recruited. Exome sequencing, Sanger sequencing, and bioinformatics tools were conducted to identify the mutation in this pedigree. HaCaT cells were transfected with either wild-type or mutated KRT9. Confocal laser immunofluorescence assay, imaging processing, and statistical analysis were performed to evaluate wild-type and mutant KRT9 groups. Results: A novel heterozygous c.1369C>T transition (p.Leu457Phe) in exon 6 of the KRT9 gene was identified in four patients. It cosegregated with the disorder in the family. Functional analysis showed that withdrawal of the filament network from the cell periphery and particle formation were present in about $10 \%$ of Leu457Phe-transfected HaCaT cells, while approximately $3 \%$ of cells transfected with wildtype KRT9 showed this phenotype. The particles in mutant group were larger than that in wildtype group $(P$-value $<0.05)$. Conclusion: The variant may be the disease-causing missense mutation and produce dominant negative effects by interrupting keratin network formation. This study indicates the pathogenic role of the KRT9 gene mutation in this pedigree with EPPK, and may be helpful in genetic counseling, prenatal diagnosis and gene-targeted therapies of EPPK.

(C) 2018 The Author(s)

Published by S. Karger AG, Basel

H. Xiao and Y. Guo contributed equally to this work.

Hao Deng

and Hongwei Lu

Centre for Experimental Medicine, the Third Xiangya Hospital, Central South University, 138 Tongzipo Road, Changsha, Hunan (China)

Tel.86-731-88618372, E-Mail hdeng008@yahoo.com, hwlv2226@163.com
\end{abstract}

KARGER 


\section{Introduction}

Epidermolytic palmoplantar keratoderma (EPPK, OMIM 144200) is a highly penetrant autosomal dominant genodermatosis [1, 2], which was first described by Vörner in 1901 [3]. It has a prevalence of 1.0 to 4.4 per 100, 000 without sex predilection [4-6]. The typical clinical feature of EPPK is diffuse yellow keratoses over the entire epidermis of palms and soles, with a well-demarcated erythematous border [7, 8]. Other features are knuckle pads on the digital joints, clubbing of the nails [1], camptodactyly [9], digital mutilation [10], hyperhidrosis, increased sensitivity of the palms and soles to mechanical trauma $[1,11]$, and decreased heat sensitivity [12]. It usually manifests shortly after birth [7]. Rarely, EPPK has been reported to be associated with woolly hair and heart diseases [13], or with breast and ovarian tumour in a large pedigree [14].

Histologically, palmoplantar epidermis presents varying degrees of dyskeratosis and epidermolytic hyperkeratosis, including pronounced perinuclear vacuolization of the keratinocytes and huge keratohyalin granules located in the upper stratum spinosum [1517]. Ultrastructural analysis reveals abnormal perinuclear tonofilament clumping and the presence of large and distorted keratohyalin granules [6].

Keratins are a multigene family that are generally expressed in specific type I (acidic)/ type II (neutral or basic) keratin pairs [18, 19]. In 1991, a gene for EPPK was mapped to the region of the type I keratin gene cluster at chromosome 17q12-q21 with linkage analysis in a large pedigree from Northwest Germany [15]. The keratin 9 gene (KRT9, OMIM 607606), one of the type I keratin genes, was proposed as the candidate gene for EPPK due to its exclusive expression in epidermal keratinocytes of the palms and soles [15, 20, 21]. Subsequently, KRT9 gene mutations were reported as a causative genetic factor for EPPK [7]. To date, at least 28 mutations in the KRT9 gene have been described in the Human Intermediate Filament Database (HIFD) and the Human Gene Mutation Database (HGMD) [22].

In this study, we identified a novel heterozygous c.1369C $>\mathrm{T}$ transition (p.Leu457Phe) in the KRT9 gene in a four-generation Han Chinese pedigree with EPPK, and the variant cosegregated with the disease condition in the family and was absent in 200 normal controls, supporting that it may be a disease-causing mutation for EPPK in this family. In vitro studies further indicated the involvement of the KRT9 gene mutation in the pathogenic mechanism responsible for EPPK in this pedigree.

\section{Materials and Methods}

\section{Pedigree and participators}

A four-generation Han Chinese pedigree consisting of 15 individuals was referred from the Third Xiangya Hospital, Central South University, China (Fig. 1A). Peripheral blood samples and clinical data were collected from 11 pedigree members, consisting of four individuals affected with EPPK (II:1, II:5, III:2, and III:3) and seven unaffected members (I:2, III:1, III:4, III:5, III:6, IV:1, and IV:2). Blood specimens were also obtained from 200 unrelated ethnically-matched normal controls (male/female: 100/100; mean age, $34.2 \pm 4.5$ years). Written informed consent was obtained from all the participating individuals or their parents. This study was carried out according to the Declaration of Helsinki, and had received approval from the Institutional Review Board of the Third Xiangya Hospital, Central South University, China.

\section{Exome capture}

Peripheral blood genomic DNA (gDNA) was extracted from leukocytes as previously described [23]. Paired-end DNA library was generated according to the manufacturer's instructions (Agilent Technologies Inc., USA). Genomic DNA was fragmented into 180-280 bp with the use of sonication. Capture enrichment was performed by using an Agilent SureSelect Human All Exon V5 Kit. The enriched DNA library was sequenced on a HiSeq 2000 platform (Illumina Inc., USA) [24]. 


\section{Cellular Physiology Cell Physiol Biochem 2018;46:1919-1929 \begin{tabular}{l|l} 
and Biochemistry POI: 10.1159/000489381 2018 & $\begin{array}{l}\text { (c) 2018 The Author(s). Published by S. Karger AG, Basel } \\
\text { www.karger.com/cpb }\end{array}$
\end{tabular}}

Xiao et al.: A Novel Keratin 9 Mutation and EPPK

\section{Variant analysis}

Following sequencing on the HiSeq 2000 platform, the primary data was converted to a FASTQ format and processed to retrieve high quality paired-end reads, which were aligned to human reference genome sequence (UCSC database, GRCh37/hg19) using Burrows-Wheeler Alignment tool [25]. High quality alignment was essential to guarantee variant calling accuracy (greater than 0) so as to identify single nucleotide polymorphisms (SNPs) and insertions-deletions (indels). The analysis-ready Binary Alignment/ Map (BAM) alignment results were produced after being processed through SAMtools, Genome Analysis Toolkit, and Picard. SNPs were called using parameters as previously described $[26,27,28]$. SNPs and indels were annotated using Annotate Variation (ANNOVAR), and filtered against databases including the SNPS build 142 (dbSNP142), the 1000 Genomes Project (2014 September release), the NHLBI exome sequencing project (ESP) 6500, and an in-house exome database from Novogene Bioinformatics Institute using 700 ethnically-matched controls. A prioritization process was used as previously described [28]. After this step was performed, any retained variants were taken as "novel" variants. A functional prediction was performed by submitting non-synonymous SNPs to Polymorphism Phenotyping version 2 (PolyPhen-2) and Sorting Intolerant from Tolerant (SIFT, http://sift.jcvi.org/) as previously described [28, 29].

Variants were selected for validation when the bioinformatics tools predicted that a variant was disease-causing. Primer3 program was used to design locus-specific primers, and Primer-BLAST (Basic Local Alignment Search Tool) to determine Primer specificity. The forward primer sequence was 5'-CCCCAGGATGAAGAAGTCCT-3', and the reverse primer sequence was 5'-CAAGAGATCGAGTGCCAGAA-3'. Sanger sequencing was performed in the proband, available pedigree members and the 200 normal controls to verify the potential pathogenic variant $[30,31]$.

Multiple protein sequence alignment among a variety of species was performed using Clustal Omega (http://www.ebi.ac.uk/Tools/msa/clustalo/). SIFT, PolyPhen-2, MutationAssessor, and MutationTaster were used to predict the probable influence of the amino acid residue substitution on protein function in order to further analyse the variant's assumed pathogenicity [29, 32, 33].

\section{Plasmid construction}

To generate expression constructs for wild-type and mutant KRT9 fusion proteins tagged with EGFP, a human KRT9 cDNA was amplified with primers 5'-TACCGGACTCAGATCTCGAGCGCCACCATGAGCTGCAGACAGTTCTCCTC-3' and 5'-GATCCCGGGCCCGCGGTACCGTGGAATGGGATGATTTTCCGCTTC-3', and cloned into the XhoI/ KpnI restricted pEGFP-N1 vector. The identified missense mutation (c.1369C>T, p.Leu457Phe) was introduced into the wild-type KRT9 expression clone by site-directed mutagenesis using primers 5'-CTACCACAACTTCCTTGAGGGAGGCCAGGAAG-3' and 5'-TCCCTCAAGGAAGTTGTGGTAGGTCTCGATTTCC-3'. The cDNA clones were sequenced in both directions to confirm that no additional non-synonymous mutations had been introduced during mutagenesis.

\section{Cell culture, transfection and immunofluorescence staining}

HaCaT cells were maintained in Dulbecco's modified Eagle's medium (Gibco, Carlsbad, CA, USA) supplemented with $10 \%$ fetal calf serum (FCS) at $37^{\circ} \mathrm{C}$ and $5 \% \mathrm{CO}_{2}$. HaCaT cells were grown on glass coverslips in a 6-well plate (Costar, Cambridge, MA, USA). Transient transfection was performed at 7080\% confluency using Lipofectamine ${ }^{\mathrm{TM}} 3000$ (Invitrogen, Carlsbad, CA, USA) following the manufacturer's protocols. At $72 \mathrm{~h}$ post-transfection, cells were fixed in $4 \%$ paraformaldehyde and permeabilized in $0.2 \%$ Triton X-100 for $30 \mathrm{~min}$. Transfected cells were processed to recognize the tubulin network by staining with mouse monoclonal anti- $\alpha$-tubulin antibody T6199 at a dilution of 1:200 (Sigma, St Louis, MO, USA). A Cy3conjugated sheep anti-mouse IgG C2181 (Sigma, St Louis, MO, USA) was used as the secondary antibody at a dilution of 1:100. Nuclei were stained with DAPI. Observations were performed with a Carl Zeiss LSM 800 confocal laser scanning microscope.

\section{Image processing and statistical analysis}

Cells containing particles were visualized using an Olympus IX71 microscope (Olympus, Tokyo, Japan), and images were captured using an imaging software (Olympus cellSens Standard ver. 1.2.1). To quantify and compare particle sizes in wild-type and mutant KRT9 groups, we assumed that fluorescence area is directly proportional to the particle size. Fluorescence areas for 3287 particles (60 cells) in mutant group 


\section{Cellular Physiology Cell Physiol Biochem 2018;46:1919-1929 \begin{tabular}{l|l} 
DOI: 10.1159/000489381 & Ond 2018 The Author(s). Published by S. Karger AG, Basel \\
wwww.karger.com/cpb
\end{tabular} Xiao et al.: A Novel Keratin 9 Mutation and EPPK}

and 2147 particles (50 cells) in wild-type group were measured using ImageJ programme (https://imagej. net/Particle_Analysis). Statistical analyses were performed using the PASW Statistics 18 (SPSS Inc., Chicago, IL, USA), and comparison of particle sizes in these two groups was performed using the independentsamples $t$-test to calculate the $P$-value. Significance level was set at $P<0.05$.

\section{Results}

\section{Clinical data}

The proband (III:2) was a 43 year-old man having diffuse hyperkeratosis with welldemarcated erythematous margins on his palms and soles since infancy (Fig. 1B). Skin scaling was also observed on his soles. All other family members affected with EPPK had clinical appearances similar to the proband but to varying degrees. No evidence of knuckle pads, digital mutilation, camptodactyly, hyperhidrosis, or other symptoms were observed in the pedigree. The clinical characteristics of EPPK-affected family members are summarized in Table 1.

\section{Mutation analysis}

By exome sequencing of proband gDNA, a total of 37.85 million reads were generated, with 37.80 million reads (99.88\%) mapped to the human reference genome, and 3, 605.20 $\mathrm{Mb}$ of effective sequences mapped to the target sequence region. The average sequencing depth on the target region was 71.55 [28]. Aligned bases covered 99.7\% (50.24 million bases) of the target region, $97.0 \%$ of which was covered at $10 \times$ or greater. In total, 96,123 SNPs and 9, 659 indels were detected. The previously-described prioritization scheme was used to identify the probable variant in the patient [28,34]. It was eliminated that commonlyknown variants documented in public databases, consisting of the 1000 Genomes Project with a frequency $>0.5 \%$, the dbSNP142 (minor allele frequency, MAF $>1 \%$ ), and the NHLBI ESP6500, and synonymous variants. PolyPhen-2 and SIFT were used to predict the possible effects of non-synonymous variants on protein function. No known disease-causing variants in palmoplantar keratoderma-associated genes were found, except for a missense variant c.1369C>T (p.Leu457Phe) in the KRT9 gene was discovered for EPPK.

Sanger sequencing validated the heterozygous c. $1369 \mathrm{C}>\mathrm{T}$ variant in exon 6 of the KRT9 gene identified in the proband. This variant was also identified in other affected family members (II:1, II:5, and III:3), but was absent in the unaffected family members (I:2, III:1, III:4, III:5, III:6, IV:1, and IV:2) and the 200 normal controls (Fig.

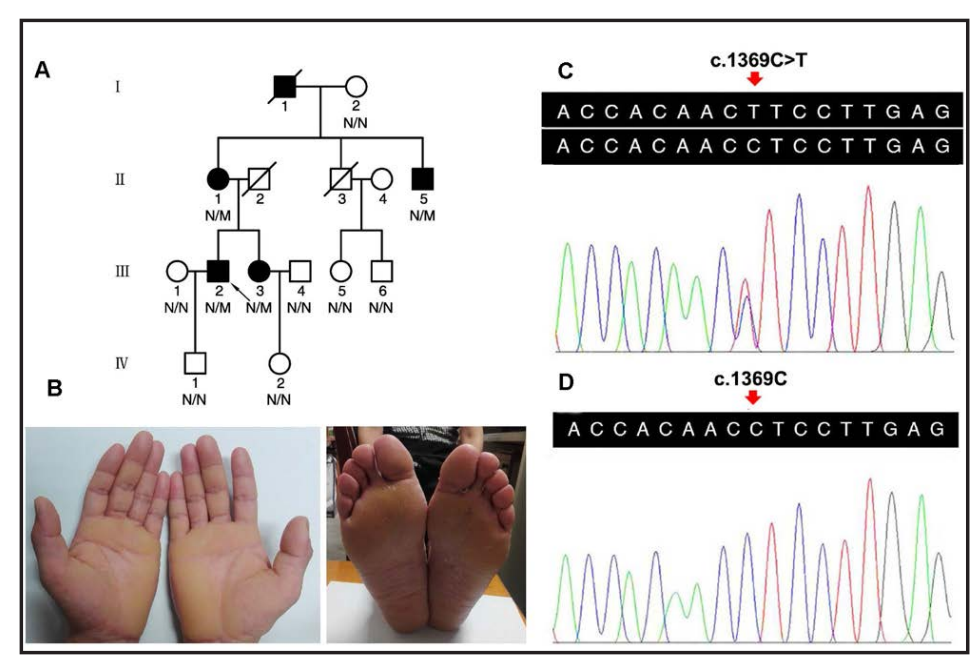

Fig. 1. Genetic analysis of the EPPK family. (A) Pedigree analysis of the EPPK family. Squares and circles indicate male and female family members, respectively. Individuals with symptoms are showed with black squares or circles. Arrow indicates the proband (III:2). Deceased family members are indicated with "/". N, normal; M, the KRT9 c.1369C>T transition mutation. (B) Clinical presentation of the proband. The diffuse yellowish hyperkeratosis on the surface of palms and soles was sharply bordered with erythematous margins. (C) Heterozygous c.1369C>T (p.Leu457Phe) mutation in the KRT9 gene. (D) Unaffected family member (III:1) of the family. 
1C,D). Based on multiple sequence alignment of the KRT9 protein sequences, the leucine at position 457 (p.Leu457) was shown to be highly conserved among the ten vertebrates (Fig. 2). SIFT returned a score of 0.00 , implying that the transition was predicted to be damaging. PolyPhen-2 produced a score of 0.999 based on the HumVar database (sensitivity, 0.09; specificity, 0.99). MutationAssesor produced a functional impact score of 4.105, predicting that the variant would be functional (high). MutationTaster predicted that the transition was disease-causing, with a high probability of 0.908 .

\section{Immunofluorescence} analysis of transfected HaCaT cells

At 72 hours after transfection, the cytoplasmic particle formation was present in about $10 \%$ of the Leu 457 Phe-transfected HaCaT cells, while approximately $3 \%$ of the cells transfected with wildtype KRT9 showed this phenotype (Fig. 3). The particles in mutant group were larger than that in wild-type group ( $P$-value $<0.05$ ). However, tubulin indicated by red signal was not apparently different in these two groups.

Table 1. Clinical characteristics of four family members affected with EPPK. ЕРPK, epidermolytic palmoplantar keratoderma

\begin{tabular}{lcccc}
\hline & II:1 & II:5 & III:2 & III:3 \\
\hline Age (years) & 66 & 57 & 44 & 43 \\
Age of onset & Infancy & Infancy & Infancy & Infancy \\
Gender & Female & Male & Male & Female \\
Diffuse hyperkeratosis confined to palms or & Palms and & Palms and & Palms and & $\begin{array}{c}\text { Soles and slight } \\
\text { hyperkeratosis on }\end{array}$ \\
soles, with well-demarcated erythematous & soles & soles & soles & palms \\
margins & No & No & No & No \\
Knuckle pads on the finger joints & Yes & No & No & Yo \\
Painful fissuring & Yes & Yes & Yes & No \\
Scaling & No & No & No & No \\
Digital mutilation & No & No & No & No \\
Camptodactyly & No & No & No & No \\
Hyperhidrosis & Yes & No & No & No \\
Increased sensitivity of palms and soles to & Yes & No & No & No \\
mechanical insult & No & No & No & No \\
Decreased sensitivity to heat & No & No & No & No \\
Other affected areas (wrists and nails) & & & & \\
Associated diseases (tumour and heart & & & & \\
disease) & & & \\
\hline
\end{tabular}



Fig. 2. Conservation analysis of the KRT9 p.Leu457 amino acid residue.

Fig. 3. Immunofluorescence assay of transfected HaCaT cells. Particles in Leu457Phe-transfected cells (top row) were distributed in the cell periphery, with a fiber structure partially remained in the central cytoplasm. Expression of wild-type KRT9 proteins in wttransfected cells showed discrete particles distributed in the entire cytoplasm (second row) or a fiber structure (third row). The tubulin was not apparently different in these two cell groups. Note: KRT9, tubulin and nucleus were indicated by green, red and blue signals, respectively. wt, wild-type.

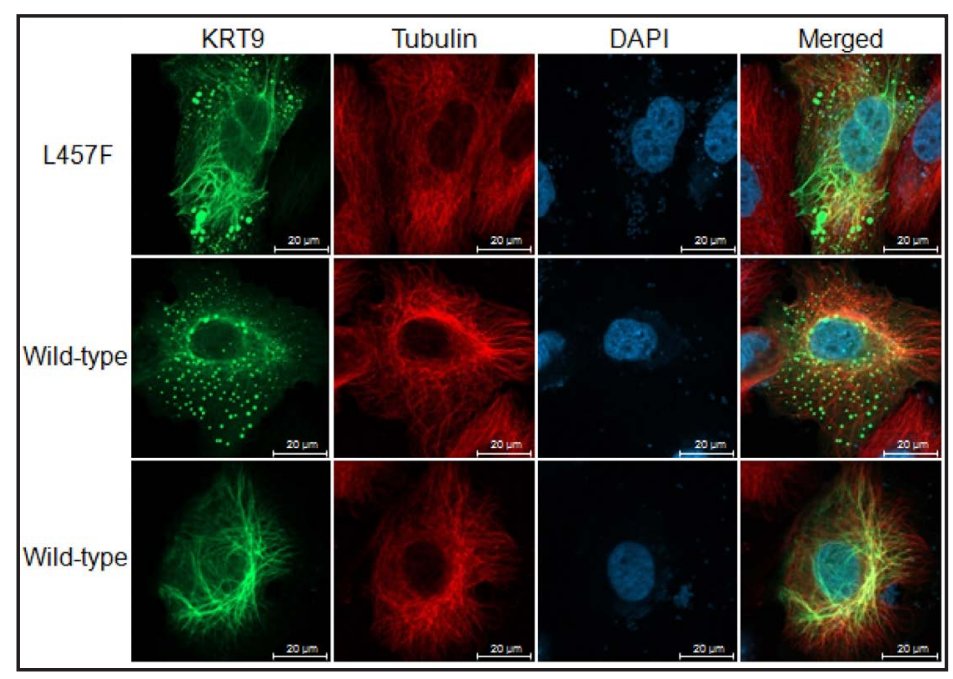


Fig. 4. Schematic representation of the reported KRT9 gene mutations in epidermolytic palmoplantar keratoderma. The KRT9 (NM_000226.3, NP_000217.2) protein structure is a central $\alpha$-helix rod domain flanked by nonhelical head and tail domains at both ends. The rod domain is composed of four coils $(1 \mathrm{~A}, 1 \mathrm{~B}, 2 \mathrm{~A}$, and 2B) isolated by nonhelical linkers (L1, L12, and L2). Most of the KRT9 gene mutations are located in the coils $1 \mathrm{~A}$ and $2 \mathrm{~B}$.

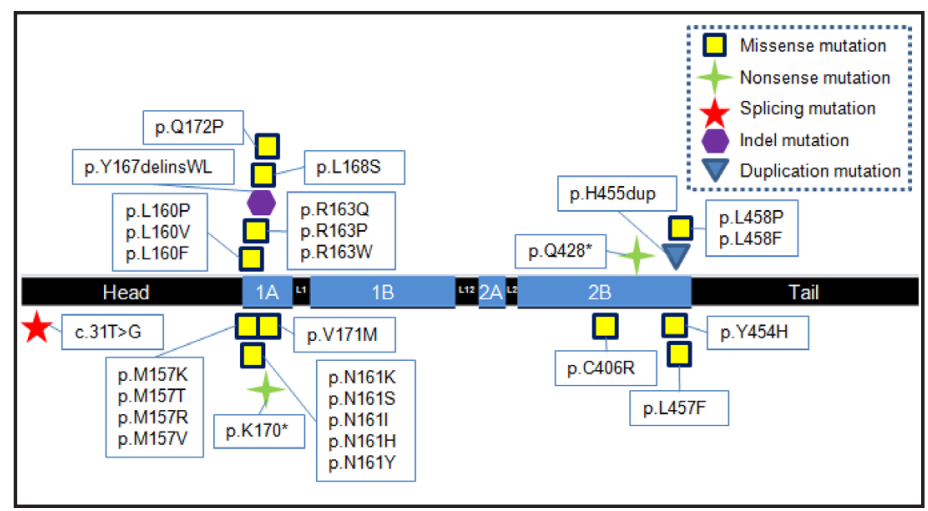

\section{Discussion}

EPPK is the most common hereditary keratoderma [4]. It is characterized by uniform epidermal thickening, with well-demarcated erythematous margins, confined to palms and soles $[8,15,35]$. Mutations in the KRT9 gene and less frequently in the keratin 1 gene (KRT1, OMIM 139350) were reportedly responsible for EPPK [8, 36, 37]. Presently, 82.1\% (23/28) of the KRT9 gene mutations are missense mutations occurred in helix boundary motifs (shown in Fig. 4, according to the HIFD and the HGMD).

The KRT9 gene belongs to the type I keratin gene cluster, includes eight exons, and encodes 623 amino acids (NCBI GenBank database). Keratins are part of the intermediate filament superfamily, constituting the major portion of structural proteins in epithelial cells [38]. They not only provide support to resist traumatic damage to the cell [5], but also are involved in cell migration, differentiation, and proliferation [39]. The common keratin structure is a central, primarily $\alpha$-helix rod domain flanked by nonhelical head and tail domains at both ends [40]. The rod domain is composed of four coils $(1 \mathrm{~A}, 1 \mathrm{~B}, 2 \mathrm{~A}$, and 2B) isolated by nonhelical linkers (L1, L12, and L2) (Fig. 4) [41]. Type I and type II keratin proteins form heterodimers, via a coiled-coil interaction of two $\alpha$-helices. The interaction is promoted by heptad repeats located in the central rod region [2]. Two short highly-conserved boundary regions, the helix initiation motif (HIM) and the helix termination motif (HTM), in which most causative mutations occur, are located at the beginning and the end of the rod domain [40-42]. EPPK is generally believed to be caused by the dominant negative effect of the KRT9 mutants located in the HIM and HTM regions [41-43].

This study identified a novel p.Leu457Phe variant of the KRT9 gene in a Han Chinese family with EPPK. The variant co-segregated with the EPPK phenotype in this family, and was absent from public databases and the 200 normal controls, implying that this variant may be disease-causing. Though both leucine and phenylalanine are hydrophobic amino acids, p.Leu 457 is phylogenetically conserved among various vertebrates (Fig. 2). Bioinformatics tools predicted that the variant was "disease-causing". The final 10-11 residues of the $2 \mathrm{~B}$ rod domain of one keratin molecule overlap with the first 10-11 residues of the $1 \mathrm{~A}$ rod domain of its neighbor [20]. This is considered important to keratin intermediate filament assembly through end-to-end interactions [36]. The p.Leu457 residue of the KRT9 gene is the second of the last ten amino acids in the $2 \mathrm{~B}$ rod segment [44]. A mutation of it may produce dominant negative effects by interrupting the formation of keratin intermediate filaments [41]. An adjacent mutation (p.Leu458Phe, previously mislabeled "p.Leu457Phe") in the same segment was reported to be responsible for EPPK in a Japanese kindred [45], confirming the importance of the region (HIFD). Data recorded in the HIFD and the HGMD showed that $92.0 \%(80 / 87)$ of the KRT9 gene mutations identified in independent EPPK families were located in exon 1 ranging from p.Met157 to p.Gln172, and 6.9\% (6/87) in exon 6 . This study tends to show that the $2 \mathrm{~B}$ rod domain of the KRT9 protein is a conserved 


\section{Cellular Physiology Cell Physiol Biochem 2018;46:1919-1929 \begin{tabular}{l|l} 
DOI: 10.1159/000489381 & $\begin{array}{l}\text { O 2018 The Author(s). Published by S. Karger AG, Basel } \\
\text { www.karger.com/cpb }\end{array}$
\end{tabular} \\ Xiao et al.: A Novel Keratin 9 Mutation and EPPK}

domain, and that exon 6 of the KRT9 gene is a second potential target for EPPK therapies except for exon 1 [5].

Keratin filament sources consist of newly produced keratin particles and soluble subunits [46]. Keratin filament networks are highly motile and dynamic [46, 47], following the keratin cycling model with keratin filament assembled primarily in the periphery, centripetal keratin flux, and disassembly in the cell center $[46,48]$. In our study, at 72 hours after transfection of HaCaT cells, $10 \%$ of the transfected cells in the mutant group and $3 \%$ of that in the wildtype group both showed perturbed endogenous keratin filament networks. Instead of forming a fiber structure, particle formation was observed in the cytoplasm. Particularly, the particles were more pronounced in the periphery of some cells, while the central part of the keratin filament network was partially remained, similar to previous reports [47, 49]. The newly formed mutant and wild-type KRT9 proteins may result in abnormal aggregation by integrating into preexisting keratin network in the periphery or the entire cytoplasm [46, $47,49]$. Although the cytoplasmic particle formation was also observed in the wild-type group, the affected cells were about one-third of that in the mutant group, and the particles were smaller than that in the mutant group $(P$-value $<0.05)$. Therefore, the keratin network was probably more severely impaired in the mutant group by previously claimed dominant negative effects $[37,43]$. The amount of over-expressed wild-type KRT9 proteins may exceed the cell abilities to eliminate surplus material, leading to a significant shift in the dynamic equilibrium of keratin cycling model [46, 47], which is consistent with microinjected type I keratin and transient transfection of wild-type KRT1 or KRT5 plasmids showing discrete particles and filament aggregation $[37,47]$. However, in our two transfected cell groups, the overall pattern of tubulin showed no apparent perturbations, similar to previous studies [50, 51].

Other in vitro and in vivo studies showed that the formation of intermediate filament network was perturbed by transfecting cells and injecting into mouse skin with the KRT9 p.Arg163Gln mutant $[38,43]$. Krt9 $\%$ mice developed hyperpigmented calluses confined to their footpads, whereas $\mathrm{Krt9}^{+/-}$mice had normal palmoplantar epidermis, suggesting that the KRT9 gene is critical for terminal differentiation and structural integrity of palmoplantar epidermis [52]. Krt9 $9^{+/ m u t}$ and $K r t 9^{\text {mut } / m u t}$ knockin mice both developed EPPK-like phenotypes by inducing an imbalance in a subset of palmoplantar keratins, demonstrating a dominant negative effect of the KRT9 mutations [53].

Among the seven KRT9 gene mutations identified in the 2B rod domain (including our mutation) $[9,10,42,45,54,55]$, five of them are closely distributed, ranging from p.Tyr454 to p.Leu458 [9, 42, 45, 54] (Fig. 4). All the patients suffered from diffuse palmar and plantar hyperkeratosis [9, 10, 42, 45, 54, 55]. Camptodactyly [9], hyperhidrosis [9, 55], and knuckle pads $[9,10,55]$, were observed in one, two, and three families, respectively. Similar to our pedigree, patients with the same KRT9 mutation showed variability of disease severity in their pedigrees $[9,55]$. This suggests that the clinical appearance may be influenced not only by the KRT9 mutations, but other genetic, epigenetic and environmental factors $[36,56]$.

Prenatal genetic diagnosis would be able to take advantage of identifying the KRT9 gene mutation in this family, and help minimize the EPPK risk $[57,58]$. The exclusive expression of the KRT9 gene, and the dominant-negative interference in EPPK may favor gene-targeted therapies delivered in situ as pachyonychia congenita [59-61]. The feasibility of this potentially personalized medicine has been shown in mouse models [53, 59], however, any potential delivery system awaits further investigation [60].

\section{Conclusion}

In summary, a novel KRT9 c.1369C>T (p.Leu457Phe) transition mutation was identified in a Han Chinese family containing EPPK sufferers. Further in vitro studies showed that intracellular stress caused by expression of the mutated KRT9 gene may function as an important factor in determining the course and outcomes of EPPK in this family. This study 


\section{Cellular Physiology Cell Physiol Biochem 2018;46:1919-1929 \begin{tabular}{l|l} 
and Biochemistry Published online:May 02, 2018 & $\begin{array}{l}\text { (c) 2018 The Author(s). Published by S. Karger AG, Basel } \\
\text { www.karger.com/cpb }\end{array}$ \\
\hline POI.1159/00048381
\end{tabular} \\ Xiao et al.: A Novel Keratin 9 Mutation and EPPK}

may promote a better understanding of the EPPK's molecular basis and contribute to prenatal diagnosis and potential gene-targeted therapies for EPPK.

\section{Acknowledgements}

We are grateful to the proband and his family; without their cooperation and contribution, this work would not have been performed. We wish to thank our clinical colleagues for their efforts in collecting clinical and genetic data. This work was funded by the National Key Research and Development Program of China (2016YFC1306604), the National Natural Science Foundation of China (81670216), the Natural Science Foundation of Hunan Province (2015JJ4088, 2016JJ2166 and 2017JJ3469), the Grant for the Foster Key Subject of the Third Xiangya Hospital of Central South University (Clinical Laboratory Diagnostics), and the New Xiangya Talent Project of the Third Xiangya Hospital of Central South University (20150301), the National Basic Research Program of China (2014CB542400), and the National-level College Students' Innovative Training Plan Program (201610533288), China. The funders had no role in study design, data collection and analysis, decision to publish, or preparation of the manuscript.

\section{Disclosure Statement}

The authors declare no conflict of interest.

\section{References}

$>1$ Küster W, Reis A, Hennies HC: Epidermolytic palmoplantar keratoderma of Vörner: re-evaluation of Vörner's original family and identification of a novel keratin 9 mutation. Arch Dermatol Res 2002;294:268272.

-2 Lu Y, Guo C, Liu Q, Zhang X, Cheng L, Li J, Chen B, Gao G, Zhou H, Guo Y, Li Y, Gong Y: A novel mutation of keratin 9 in epidermolytic palmoplantar keratoderma combined with knuckle pads. Am J Med Genet A 2003;120A:345-349.

3 Vörner H: Zur Kenntniss des Keratoma hereditarium palmare et plantare. Arch Dermatol Syph 1901;56:331.

4 Braun-Falco M: Hereditary palmoplantar keratodermas. J Dtsch Dermatol Ges 2009;7:971-984.

5 Covello SP, Irvine AD, McKenna KE, Munro CS, Nevin NC, Smith FJD, Uitto J, Irwin McLean WH: Mutations in keratin K9 in kindreds with epidermolytic palmoplantar keratoderma and epidemiology in Northern Ireland. J Invest Dermatol 1998;111:1207-1209.

6 Szalai S, Szalai C, Becker K, Török E: Keratin 9 mutations in the coil 1A region in epidermolytic palmoplantar keratoderma. Pediatr Dermatol 1999;16:430-435.

-7 Reis A, Hennies HC, Langbein L, Digweed M, Mischke D, Drechsler M, Schröck E, Royer-Pokora B, Franke WW, Sperling K, Küster W: Keratin 9 gene mutations in epidermolytic palmoplantar keratoderma (EPPK). Nat Genet 1994;6:174-179.

8 Grimberg G, Hausser I, Müller FB, Wodecki K, Schaffrath C, Krieg T, Oji V, Traupe H, Arin MJ: Novel and recurrent mutations in the $1 \mathrm{~B}$ domain of keratin 1 in palmoplantar keratoderma with tonotubules. $\mathrm{Br} \mathrm{J}$ Dermatol 2009;160:446-449.

-9 Du ZF, Wei W, Wang YF, Chen XL, Chen CY, Liu WT, Lu JJ, Mao LG, Xu CM, Fang H, Zhang XN: A novel mutation within the $2 \mathrm{~B}$ rod domain of keratin 9 in a Chinese pedigree with epidermolytic palmoplantar keratoderma combined with knuckle pads and camptodactyly. Eur J Dermatol 2011;21:675-679.

10 Umegaki N, Nakano H, Tamai K, Mitsuhashi Y, Akasaka E, Sawamura D, Katayama I: Vörner type palmoplantar keratoderma: novel KRT9 mutation associated with knuckle pad-like lesions and recurrent mutation causing digital mutilation. Br J Dermatol 2011;165:199-201. 


\section{Cellular Physiology Cell Physiol Biochem 2018;46:1919-1929

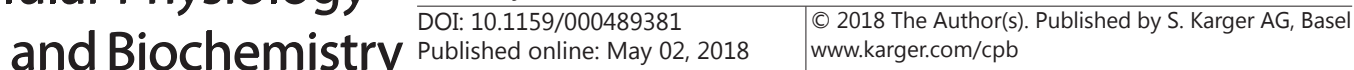 \\ Xiao et al.: A Novel Keratin 9 Mutation and EPPK}

11 Li M, Yang LJ, Hua HK, Zhu XH, Dai XY: Keratin-9 gene mutation in epidermolytic palmoplantar keratoderma combined with knuckle pads in a large Chinese family. Clin Exp Dermatol 2009;34:26-28.

12 Lopez-Valdez J, Rivera-Vega MR, Gonzalez-Huerta LM, Cazarin J, Cuevas-Covarrubias S: Analysis of the KRT9 gene in a Mexican family with epidermolytic palmoplantar keratoderma. Pediatr Dermatol 2013;30:354358.

13 Carvajal-Huerta L: Epidermolytic palmoplantar keratoderma with woolly hair and dilated cardiomyopathy. J Am Acad Dermatol 1998;39:418-421.

14 Blanchet-Bardon C, Nazzaro V, Chevrant-Breton J, Espie M, Kerbrat P, Le Marec B: Hereditary epidermolytic palmoplantar keratoderma associated with breast and ovarian cancer in a large kindred. Br J Dermatol 1987;117:363-370.

15 Reis A, Küster W, Eckardt R, Sperling K: Mapping of a gene for epidermolytic palmoplantar keratoderma to the region of the acidic keratin gene cluster at 17q12-q21. Hum Genet 1992;90:113-116.

16 Bergman R, Khamaysi Z, Sprecher E: A unique pattern of dyskeratosis characterizes epidermolytic hyperkeratosis and epidermolytic palmoplantar keratoderma. Am J Dermatopathol 2008;30:101-105.

17 Endo H, Hatamochi A, Shinkai H: A novel mutation of a leucine residue in coil 1A of keratin 9 in epidermolytic palmoplantar keratoderma. J Invest Dermatol 1997;109:113-115.

18 Steinert PM: The two-chain coiled-coil molecule of native epidermal keratin intermediate filaments is a type I-type II heterodimer. J Biol Chem 1990;265:8766-8774.

19 Irvine AD, Irwin McLean WH: Human keratin diseases: the increasing spectrum of disease and subtlety of the phenotype-genotype correlation. Br J Dermatol 1999;140:815-828.

20 Steinert PM: Structure, function, and dynamics of keratin intermediate filaments. J Invest Dermatol 1993;100:729-734.

-21 Knapp AC, Franke WW, Heid H, Hatzfeld M, Jorcano JL, Moll R: Cytokeratin No. 9, an epidermal type I keratin characteristic of a special program of keratinocyte differentiation displaying body site specificity. J Cell Biol 1986;103:657-667.

22 Szeverenyi I, Cassidy AJ, Chung CW, Lee BT, Common JE, Ogg SC, Chen H, Sim SY, Goh WL, Ng KW, Simpson JA, Chee LL, Eng GH, Li B, Lunny DP, Chuon D, Venkatesh A, Khoo KH, Irwin McLean WH, Lim YP, Lane EB: The Human Intermediate Filament Database: comprehensive information on a gene family involved in many human diseases. Hum Mutat 2008;29:351-360.

23 Yuan L, Deng X, Song Z, Yang Z, Ni B, Chen Y, Deng H: Genetic analysis of the RAB39B gene in Chinese Han patients with Parkinson's disease. Neurobiol Aging 2015;36:2907.e11-2907.e12.

24 Zheng W, Chen H, Deng X, Yuan L, Yang Y, Song Z, Yang Z, Wu Y, Deng H: Identification of a Novel Mutation in the Titin Gene in a Chinese Family with Limb-Girdle Muscular Dystrophy 2J. Mol Neurobiol 2016;53:50975102.

25 Li H, Durbin R: Fast and accurate short read alignment with Burrows-Wheeler transform. Bioinformatics 2009;25:1754-1760.

26 McKenna A, Hanna M, Banks E, Sivachenko A, Cibulskis K, Kernytsky A, Garimella K, Altshuler D, Gabriel S, Daly M, DePristo MA: The Genome Analysis Toolkit: a MapReduce framework for analyzing next-generation DNA sequencing data. Genome Res 2010;20:1297-1303.

27 Li H, Handsaker B, Wysoker A, Fennell T, Ruan J, Homer N, Marth G, Abecasis G, Durbin R, 1000 Genome Project Data Processing Subgroup: The Sequence Alignment/Map format and SAMtools. Bioinformatics 2009;25:2078-2079.

28 Yuan L, Xu H, Yuan J, Deng X, Xiong W, Yang Z, Huang Y, Deng H: A novel FN1 variant associated with familial hematuria: TBMN? Clin Biochem 2016;49:816-820.

29 Adzhubei IA, Schmidt S, Peshkin L, Ramensky VE, Gerasimova A, Bork P, Kondrashov AS, Sunyaev SR: A method and server for predicting damaging missense mutations. Nat Methods 2010;7:248-249.

-30 Yuan L, Song Z, Xu H, Gu S, Zhu A, Gong L, Zhao Y, Deng H: EIF4G1 Ala502Val and Arg1205His variants in Chinese patients with Parkinson disease. Neurosci Lett 2013;543:69-71.

-31 Guo Y, Yang H, Deng X, Song Z, Yang Z, Xiong W, Yuan L, Xu H, Deng S, Deng H: Genetic analysis of the S100B gene in Chinese patients with Parkinson disease. Neurosci Lett 2013;555:134-136.

32 Reva B, Antipin Y, Sander C: Predicting the functional impact of protein mutations: application to cancer genomics. Nucleic Acids Res 2011;39:e118.

33 Schwarz JM, Rödelsperger C, Schuelke M, Seelow D: MutationTaster evaluates disease-causing potential of sequence alterations. Nat Methods 2010;7:575-576. 


\section{Cellular Physiology Cell Physiol Biochem 2018;46:1919-1929 \begin{tabular}{l|l} 
and Biochemistry Published online: May 02, 2018 & $\begin{array}{l}\text { (c) } 2018 \text { The Author(s). Published by S. Karger AG, Basel } \\
\text { www.karger.com/cpb }\end{array}$ \\
\hline
\end{tabular}}

34 Yuan L, Wu S, Xu H, Xiao J, Yang Z, Xia H, Liu A, Hu P, Lu A, Chen Y, Xu F, Deng H: Identification of a novel PHEX mutation in a Chinese family with X-linked hypophosphatemic rickets using exome sequencing. Biol Chem 2015;396:27-33.

-35 Hatsell SJ, Eady RA, Wennerstrand L, Dopping-Hepenstal P, Leigh IM, Munro C, Kelsell DP: Novel splice site mutation in keratin 1 underlies mild epidermolytic palmoplantar keratoderma in three kindreds. J Invest Dermatol 2001;116:606-609.

-36 Terron-Kwiatkowski A, Terrinoni A, Didona B, Melino G, Atherton DJ, Irvine AD, Irwin McLean WH: Atypical epidermolytic palmoplantar keratoderma presentation associated with a mutation in the keratin 1 gene. $\mathrm{Br}$ J Dermatol 2004;150:1096-1103.

-37 Terron-Kwiatkowski A, van Steensel MA, van Geel M, Lane EB, Irwin McLean WH, Steijlen PM: Mutation S233L in the 1B domain of keratin 1 causes epidermolytic palmoplantar keratoderma with "tonotubular" keratin. J Invest Dermatol 2006;126:607-613.

38 Kobayashi S, Kore-eda S, Tanaka T: Demonstration of the pathogenic effect of point mutated keratin 9 in vivo. FEBS Lett 1999;447:39-43.

-39 Magin TM, Vijayaraj P, Leube RE: Structural and regulatory functions of keratins. Exp Cell Res 2007;313:2021-2032.

40 Zhao JJ, Zhang ZH, Niu ZM, Xiang LH, Ye XY, Huang W, Zheng ZZ: Mutation M157R of keratin 9 in a Chinese family with epidermolytic palmoplantar keratoderma. Int J Dermatol 2008;47:634-637.

-41 He XH, Zhang XN, Mao W, Chen HP, Xu LR, Chen H, He XL, Le YP: A novel mutation of keratin 9 in a large Chinese family with epidermolytic palmoplantar keratoderma. Br J Dermatol 2004;150:647-651.

\$2 Coleman CM, Munro CS, Smith FJD, Uitto J, Irwin McLean WH: Epidermolytic palmoplantar keratoderma due to a novel type of keratin mutation, a 3-bp insertion in the keratin 9 helix termination motif. Br J Dermatol 1999;140:486-490.

43 Kobayashi S, Tanaka T, Matsuyoshi N, Imamura S: Keratin 9 point mutation in the pedigree of epidermolytic hereditary palmoplantar keratoderma perturbs keratin intermediate filament network formation. FEBS Lett 1996;386:149-155.

44 Strelkov SV, Herrmann H, Geisler N, Wedig T, Zimbelmann R, Aebi U, Burkhard P: Conserved segments 1A and $2 \mathrm{~B}$ of the intermediate filament dimer: their atomic structures and role in filament assembly. EMBO J 2002;21:1255-1266.

45 Kon A, Ito N, Kudo Y, Nomura K, Yoneda K, Hanada K, Hashimoto I, Takagaki K: L457F missense mutation within the $2 \mathrm{~B}$ rod domain of keratin 9 in a Japanese family with epidermolytic palmoplantar keratoderma. Br J Dermatol 2006;155:624-626.

46 Moch M, Herberich G, Aach T, Leube RE, Windoffer R: Measuring the regulation of keratin filament network dynamics. Proc Natl Acad Sci U S A 2013;110:10664-10669.

47 Miller RK, Khuon S, Goldman RD: Dynamics of keratin assembly: exogenous type I keratin rapidly associates with type II keratin in vivo. J Cell Biol 1993;122:123-135.

-48 Werner NS, Windoffer R, Strnad P, Grund C, Leube RE, Magin TM: Epidermolysis bullosa simplex-type mutations alter the dynamics of the keratin cytoskeleton and reveal a contribution of actin to the transport of keratin subunits. Mol Biol Cell 2004;15:990-1002.

-49 Letai A, Coulombe PA, Fuchs E: Do the ends justify the mean? Proline mutations at the ends of the keratin coiled-coil rod segment are more disruptive than internal mutations. J Cell Biol 1992;116:1181-1195.

50 Miller RK, Vikstrom K, Goldman RD: Keratin incorporation into intermediate filament networks is a rapid process. J Cell Biol 1991;113:843-855.

51 Albers K, Fuchs E: The expression of mutant epidermal keratin cDNAs transfected in simple epithelial and squamous cell carcinoma lines. J Cell Biol 1987;105:791-806.

52 Fu DJ, Thomson C, Lunny DP, Dopping-Hepenstal PJ, McGrath JA, Smith FJD, Irwin McLean WH, Leslie Pedrioli DM: Keratin 9 is required for the structural integrity and terminal differentiation of the palmoplantar epidermis. J Invest Dermatol 2014;134:754-763.

53 Lyu YS, Shi PL, Chen XL, Tang YX, Wang YF, Liu RR, Luan XR, Fang Y, Mei RH, Du ZF, Ke HP, Matro E, Li LE, Lin ZY, Zhao J, Gao X, Zhang XN: A small indel mutant mouse model of epidermolytic palmoplantar keratoderma and its application to mutant-specific shRNA therapy. Mol Ther Nucleic Acids 2016;5:e299.

54 Shimomura Y, Wajid M, Weiser J, Kraemer L, Christiano AM: Mutations in the keratin 9 gene in Pakistani families with epidermolytic palmoplantar keratoderma. Clin Exp Dermatol 2010;35:759-764. 


\section{Cellular Physiology Cell Physiol Biochem 2018;46:1919-1929 \begin{tabular}{l|l|l} 
DOI: 10.1159/000489381 & O 2018 The Author(s). Published by S. Karger AG, Basel \\
www.karger.com/cpb
\end{tabular} \\ Xiao et al.: A Novel Keratin 9 Mutation and EPPK}

55 Wang K, He CD, Song F, Liu J, Chen HD: A novel mutation of the keratin 9 gene in a Chinese family with epidermolytic palmoplantar keratoderma. Int J Dermatol 2010;49:1342-1344.

56 Hamada T, Ishii N, Karashima T, Kawano Y, Yasumoto S, Hashimoto T: The common KRT9 gene mutation in a Japanese patient with epidermolytic palmoplantar keratoderma and knuckle pad-like keratoses. J Dermatol 2005;32:500-502.

57 Ke HP, Jiang HL, Lv YS, Huang YZ, Liu RR, Chen XL, Du ZF, Luo YQ, Xu CM, Fan QH, Zhang XN: KRT9 gene mutation as a reliable indicator in the prenatal molecular diagnosis of epidermolytic palmoplantar keratoderma. Gene 2014;546:124-128.

-58 Chen XL, Xu CM, Cai SR, Chen CY, Zhang XN: Prenatal diagnosis of epidermolytic palmoplantar keratoderma caused by c.T470C (p.M157T) of the keratin 9 gene in a Chinese kindred. Prenat Diagn 2009;29:911-913.

-59 Leslie Pedrioli DM, Fu DJ, Gonzalez-Gonzalez E, Contag CH, Kaspar RL, Smith FJD, Irwin McLean WH: Generic and personalized RNAi-based therapeutics for a dominant-negative epidermal fragility disorder. J Invest Dermatol 2012;132:1627-1635.

60 Roth W, Hatzfeld M, Magin TM: Targeting the palm: a leap forward toward treatment of keratin disorders. J Invest Dermatol 2012;132:1541-1542.

61 Leachman SA, Hickerson RP, Schwartz ME, Bullough EE, Hutcherson SL, Boucher KM, Hansen CD, Eliason MJ, Srivatsa GS, Kornbrust DJ, Smith FJD, Irwin McLean WH, Milstone LM, Kaspar RL: First-in-human mutation-targeted siRNA phase Ib trial of an inherited skin disorder. Mol Ther 2010;18:442-446. 